\title{
MOLECULAR DOCKING OF ANTITRYPANOSOMAL INHIBITORS FROM EUCALYPTUS TERETICORNIS FOR SLEEPING SICKNESS
}

\author{
AARTHI RASHMI B*, HARISHCHANDER A, PRIYANKA K, VASANTH NIRMAL BOSCO
}

Department of Bioinformatics, Sri Krishna Arts and Science College, Coimbatore, Tamil Nadu, India. Email: aarthirashmi@skasc.ac.in

Received: 21 June 2019, Revised and Accepted: 20 July 2019

ABSTRACT

Objectives: This study aims to investigate the antitrypanosomal inhibitors of Eucalyptus tereticornis for sleeping sickness through molecular docking and studies on Absorption distribution metabolism excursion and toxicology (ADMET).

Methods: In silico molecular docking in ArgusLab software and ADMET analysis in AdmetSAR software was performed for the antitrypanosomal inhibitors of E. tereticornis for sleeping sickness.

Results: Interactions were studied for the ten proteins responsible for sleeping sickness with the 50 antitrypanosomal inhibitors of E. tereticornis. Docking was performed to see the interaction and the best binding energy of compounds with the proteins involved in sleeping sickness. The docking scores were highest for betulonic acid with $-15.66 \mathrm{kcal} / \mathrm{mol}$ followed by euglobal with $-12.24 \mathrm{kcal} / \mathrm{mol}$, B-pinene with $-10.313 \mathrm{kcal} / \mathrm{mol}$, A-pinene with $-10.3418 \mathrm{kcal} / \mathrm{mol}$, and the least docking score for P-cymene with $-10.6045 \mathrm{kcal} / \mathrm{mol}$. Docking results showed that only betulonic acid and euglobal showed that hydrogen bond interaction was as b-pinene, a-pinene, and p-cymene yielded no hydrogen bond interactions so we will be taking the former docking results for further studies. The best docking result was shown by betulonic acid with trypanothione reductase giving binding energy of $-15.66 \mathrm{kcal} / \mathrm{mol}$ with hydrogen bond interaction of 2.9, so this result was taken for further analysis.

Conclusion: The results of the compound extracted from E. tereticornis will become physiological relevant only when (i) the pure compounds of this plant is available in large quantities; (ii) the Eucalyptus is biochemically stabilized to avoid degradation and enhance absorption in the gastrointestinal tract; and (iii) special delivery methods for this drug to reach the areas of treatment. In this work, the efficacy of E. tereticornis to act against trypanosomal protein was initiated and thus further research in this process would help us to take full advantage of the remedial effects of the compounds extracted from this plant.

Keywords: Antitrypanosomal Inhibitors, Eucalyptus tereticornis, Sleeping sickness, Molecular Docking, ADMET studies.

(c) 2019 The Authors. Published by Innovare Academic Sciences Pvt Ltd. This is an open access article under the CC BY license (http://creativecommons. org/licenses/by/4. 0/) DOI: http://dx.doi.org/10.22159/ajpcr.2019.v12i9.34632

\section{INTRODUCTION}

Human trypanosomiasis, also known as "sleeping sickness," is caused by microscopic parasites of the species Trypanosoma brucei. At present, about 10,000 new cases each year are reported to the World Health Organization occurred in India in 2007 and re-emerging these days; however, it is believed that many cases go undiagnosed and unreported. Sleeping sickness is curable with medication but is fatal if left untreated [1]. A report on a case of a 37-day-old infant from Uttar Pradesh who was presented with fever, lethargy, and convulsions, and who had a history of painful insect bite the day before admission [2]. In some cases, a pregnant woman can pass the infection to her fetus. In theory, the transmission of infection can also be by the transfusion of blood or sexual contact, but such cases were rarely documented [3]. The course of untreated infection rarely lasts longer than 6-7 years and more often kills in about 3 years [4]. The widely used criteria for defining the second stage in disease are the observation of trypanosomes in CSF or a white blood cell count of six or higher. Other indications of the second-stage disease include elevated protein and an increase in nonspecific immunoglobulin $M$ in CSF [5]. Medicinal plants have served as raw materials for natural product isolation and screening. Cetraria islandica is a well-known medicinal plant commonly referred to as Iceland moss [6]. Mosses have yielded very interesting bioactive compounds in the past. Previous studies have yielded from $C$. islandica, usnic acid and isousnic acid, protolichesteric acid, myelochroic acid, lichesterinic acid, praesorediosic acid, phaseolin acid, and dihydropertusaric acid, also the naphthazarin, hybocarpone, naphthoquinones, anthraquinones, and dibenzofurans. The present study demonstrates in vitro antitrypanosomal activity of four isolated phytoconstituents from lichen $C$. islandica and supporting evidence with the help of docking studies [7]. Antimicrobial activity was studied on the basis of the phytochemical analysis of methanolic extracts from the bark and leaf of Eucalyptus tereticornis [8].

The goal of the current study was to identify the protein targets that the medicinal plants target selectivity for phytochemical classes. In doing so, we have theoretically identified the strongly interacting plant chemicals and their biomolecular targets. These results should lead to further research to verify the efficacy of phytochemical agents [8]. In silico screening of small molecules has been at the forefront of drug discovery in recent years. There are various drug targets in T. brucei. These include trypanothione reductase (TR), rhodesain, triosephosphate isomerase (TIM), and farnesyl diphosphate synthase, in line with the fact that target-based drug discovery efforts remain a front runner in lead identification $[9,10]$. The clinical significance of the young febrile infant was malaria, bacterial sepsis, or viral fever. The clinical diagnosis of trypanosomiasis was surprising and incidental because this parasitic infection in humans is very rare in India. The characteristic morphology and the polymerase chain reaction made the diagnosis unequivocal. However, a causal association between the parasite and the febrile illness is difficult to establish [11]. The patient was treated with suramin, a drug used for the treatment of human African trypanosomiasis. The authors hypothesized that the patient was infected by a wound in the index finger while delivering an infected cattle or a bite by the flies of Tabanidstriatus to transmit infection in animals. Subsequently, a serologic study was conducted in the same village, and it illustrated that the sera of 81 of 1806 people $(4.5 \%)$ 
were seropositive for Trypanosoma evansi infection by the card agglutination test but none had parasitemia on peripheral blood [11].

\section{METHODS}

Bioinformatics is vital to significantly improve the position and function of molecules in binding and simulation. In bioinformatics, the process of computer-aided drug design (CADD) exists as a specialized discipline to use the computational [12] methods to simulate the interactions between a drug and a receptor. CADD methods are heavily dependent on bioinformatics tools, applications, and databases. The small molecules used in this study have been taken from literature survey; they have been selected on the criteria that these ligands have not been used prior used as antitrypanosomal studies. The structures of the ligand were downloaded directly from PubChem.

\section{Retrieval of the target protein}

The 3D structures of the target trypanosomal proteins were downloaded from the Protein data bank database (PDB) in.pdb format.

\section{Protein preparation}

Protein-ligand docking studies [13] were carried out based on the crystal structures of T. brucei adenosine kinase, TbAK (PDB 2xtb and PDB 3otx), T. brucei pteridine reductase 1 (TbPTR1), TbPTR1 (PDB 3jq7), T. brucei dihydrofolate reductase (TbDHFR), TbDHFR (PDB 3rg9 and PDB 3qfx), T. brucei trypanothione reductase, T. brucei cathepsin B, T. brucei heat shock protein 90 (TbHSP90), TbHSP90 (PDB 3omu and PDB 3opd), T. brucei sterol $14 \alpha$-demethylase, T. brucei nucleoside hydrolase (TbNH), TbNH (PDB 3fz0), T. brucei TIM (TbTIM), and TbTIM (PDB 1iih, T. brucei nucleoside 2-deoxyribosyltransferase, and T. brucei ornithine decarboxylase, TbODCPDB 1njj). The solvent molecules and the cocrystallized ligands were removed from the crystal structure. To be used as a receptor for docking, protein structures should be processed. Some of the typical operations include (i) addition of hydrogen atoms, (ii) elimination of water molecules that are not involved in ligand binding, and (iii) making binding groups. This was done in ArgusLab.

\section{Protein-ligand interaction using ArgusLab}

The compounds isolated from the plants were docked against the proteins using ArgusLab, to find the reasonable binding geometries and explore the protein-ligand interactions. Docking of the protein-ligand complex was mainly targeted to the predicted active site only. The selected residues of the receptor were defined to be a part of the binding site. All the compounds in the dataset were docked into the active site of the protein following the same procedure. After docking, the docked protein (protein-ligand complex) was analyzed to investigate the type of interactions. The poses of docking were saved for each compound and ranked according to their function. The pose having the highest dock score was selected for further analysis [14] (QSAR studies).

\section{RESULTS}

This study was conducted to understand the interactions between the proteins and the ligand to discover their binding affinity. This docking study was executed using ArgusLab. The 3D structure of the trypanosomal protein was downloaded from PDB and used as a target for docking. The results are as follows.

\section{Protein's binding site prediction}

CASTp was used for predicting the binding site of the protein. The active site of protein comprises of amino acid for 30TX, 3QFX, 3JQ7, 3FZO, 2XTB, 1NJJ, 3RG9, and 1IIH is listed in Tables 1-8.

In Table 1, the position of amino acids in the active sites of the protein with PDB id 30TX was analyzed by CASTp server.

In Table 2, the position of amino acids in the active sites of the protein with PDB id 3QFX was analyzed by CASTp server.

In Table 3, the position of amino acids in the active sites of the protein with PDB id 3JQ7 was analyzed by CASTp server.
Table 1: Active sites of the protein with PDB id 30TX

\begin{tabular}{lll}
\hline S. No. & Amino acid & Active sites \\
\hline 1 & Cystine & $12,123,239$ \\
2 & Arginine & $7,34,58,70,94,132,156,223,245,265$, \\
& & 316,332 \\
3 & Asparagine & $13,56,67,195,222,231,295$ \\
4 & Leucine & $15,16,39,134,138,286$ \\
5 & Aspergin & $17,92,238,266,287,289,293,299$ \\
6 & Serine & $19,64,197,269$ \\
7 & Alanine & $20,37,78,102,111,136,153,198,157$, \\
& & $221,297,300,326$ \\
8 & Histidine & $21,105,114,224,323$ \\
9 & Glucine & $33,101,104,106,131,160,225,279,268$, \\
& & $241,228,328,339$ \\
10 & Glycine & $35,62,63,81,107,129,298,296$ \\
11 & Threonine & $36,85,172,264,270,280,325$ \\
12 & Isoleucine & $38,90,108,127,267,292,330$ \\
13 & Proline & $55,61,199,282,284,338$ \\
14 & Valine & $57,60,68,71,98,109,283,240,125,278$, \\
& & 291,329 \\
15 & Tyrosine & $59,79,95,165$ \\
16 & Glutamine & $73,77,203,285,288,327$ \\
17 & Trypsin & 74 \\
18 & Lysins & $80,82,97,100,130,227,340$ \\
19 & Methionine & $110,294,302$ \\
20 & Phenylalanine & $169,200,301$ \\
\hline
\end{tabular}

Table 2: Active sites of the protein with PDB id 3QFX

\begin{tabular}{lll}
\hline S. No. & Amino acid & Active sites \\
\hline 1 & Arginine & $59,84,95,100,107,183$ \\
2 & Leucine & $90,97,105$ \\
3 & Aspergin & $43,45,54,88,120$ \\
4 & Serine & $89,98,106,108,192,216$ \\
5 & Alanine & 34,226 \\
6 & Histidine & 182 \\
7 & Glycine & $42,44,45,83,136,161,162,163$ \\
8 & Threonine & $46,86,164,184$ \\
9 & Isoleucine & $41,47,51,118,160,165$ \\
10 & Proline & $48,52,91,92,119$ \\
11 & Valine & $32,33,195$ \\
12 & Glutamine & 50,234 \\
13 & Trypsin & 57,166 \\
14 & Lysins & $85,93,123,235$ \\
15 & Methionine & 55,82 \\
16 & Phenylalanine & $58,94,233$ \\
\hline
\end{tabular}

Table 3: Active sites of the protein with PDB Id 3JQ7

\begin{tabular}{lll}
\hline S. No. & Amino acid & Active sites \\
\hline 1 & Arginine & $89,98,106,108,192,216$ \\
2 & Leucine & $90,97,105,137,168$ \\
3 & Aspergin & $46,86,164,184$ \\
4 & Serine & $43,45,54,88,120$ \\
5 & Alanine & 34,226 \\
6 & Histidine & $52,60,101$ \\
7 & Glycine & $42,44,45,83,136,161,162,163$ \\
8 & Threonine & $46,86,164,184$ \\
9 & Isoleucine & $41,47,51,118,160,165$ \\
10 & Glutamine & 50,234 \\
11 & Trypsin & 30,168 \\
12 & Lysins & $85,93,123,235$ \\
13 & Methionine & $55,90,100,105$ \\
14 & Phenylalanine & $55,98,133$ \\
\hline
\end{tabular}

In Table 4, the position of amino acids in the active sites of the protein with PDB id 3FZO was analyzed by CASTp server

In Table 5, the position of amino acids in the active sites of the protein with PDB id 2XTB was analyzed by CASTp server. 
Table 4: Active sites of the protein with PDB id $3 F Z 0$

\begin{tabular}{lll}
\hline S. No. & Amino acid & Active sites \\
\hline 1 & Serine & $20,56,88$ \\
2 & Alanine & $34,56,123,226$ \\
3 & Histidine & $136,161,162,163$ \\
4 & Glycine & $42,44,45,83$ \\
5 & Threonine & $46,86,164,184$ \\
6 & Isoleucine & $28,51,118,160,165$ \\
7 & Glutamine & $52,60,10150,234$ \\
8 & Trypsin & $30,123,235$ \\
9 & Lysins & $85,93,168$ \\
10 & Methionine & $155,290,305$ \\
11 & Phenylalanine & 133 \\
\hline
\end{tabular}

Table 5: Active sites of the protein with PDB id 2XTB

\begin{tabular}{lll}
\hline S. No. & Amino acid & Active sites \\
\hline 1 & Cystine & $25,33,140$ \\
2 & Arginine & $57,60,68,71,98,109,283,240$ \\
3 & Asparagine & $125,278,291,329$ \\
4 & Alanine & $19,64,197,269$ \\
5 & Histidine & $21,105,114,224,323$ \\
6 & Glucine & $33,101,104,106,131,160,225,279$, \\
& & $268,241,228,328,339$ \\
7 & Glycine & $35,62,63,81,107,129,298,296$ \\
8 & Threonine & $36,85,172,264,270,280,325$ \\
9 & Isoleucine & $38,90,108,330125,278,291,329$ \\
10 & Proline & $55,61,199,282,284,338127,267,292$ \\
11 & Valine & $57,60,68,71,98,109,283,240$ \\
12 & Tyrosine & $59,79,95,165$ \\
13 & Glutamine & $73,77,203,82,97,100,130,227$ \\
14 & Trypsin & 301 \\
15 & Lysins & $80,285,288,327340$ \\
16 & Methionine & 200,74 \\
17 & Phenylalanine & $169,110,294,302$ \\
\hline
\end{tabular}

Table 6: Active sites of the protein with PDB id 1NJJ

\begin{tabular}{lll}
\hline S. No. & Amino acid & Active sites \\
\hline 1 & Arginine & $33,35,106,108,192,216,289$ \\
2 & Leucine & $105,137,168,190,197,206$ \\
3 & Aspergin & $46,86,164,184$ \\
4 & Serine & $43,45,54,88,120$ \\
5 & Alanine & 34,226 \\
6 & Histidine & $52,60,101$ \\
7 & Glycine & $42,44,45,83,136,161,162,163$ \\
8 & Threonine & $46,86,164,184$ \\
9 & Isoleucine & $50,41,47,51$ \\
10 & Glutamine & 234 \\
11 & Trypsin & 30,168 \\
12 & Lysins & $55,98,133$ \\
13 & Methionine & $55,90,100,105$ \\
14 & Phenylalanine & $85,93,123,235$ \\
\hline
\end{tabular}

In Table 6, the position of amino acids in the active sites of the protein with PDB id 1NJJ was analyzed by CASTp server.

In Table 7, the position of amino acids in the active sites of the protein with PDB id 3RG9 was analyzed by CASTp server.

In Table 8, the position of amino acids in the active sites of the protein with PDB id 1IIH was analyzed by CASTp server.

\section{Docking of proteins with plant compounds}

In this study, the interactions between the ligands and various trypanosomal proteins were explored to check their binding affinity; docking study was performed using ArgusLab. The interaction between the protein and ligand was analyzed on the basis of binding energy and the results are compiled in Tables 9-17.
Table 7: Active sites of the protein with PDB id 3RG9

\begin{tabular}{|c|c|c|}
\hline S. No. & Amino acid & Active sites \\
\hline 1 & Cystine & $\begin{array}{l}20,37,78,102,111,136,153,198 \\
157,221,297,300,326\end{array}$ \\
\hline 2 & Arginine & $223,245,265,316,332$ \\
\hline 3 & Asparagine & $13,56,67,195,222,231,295$ \\
\hline 4 & Leucine & $7,34,5870,94,132,156$ \\
\hline 5 & Aspergin & $17,92,238,266,287,289,293,299$ \\
\hline 6 & Serine & $15,16,39,134,138$ \\
\hline 7 & Alanine & $28619,64,197,269,12,123,239$ \\
\hline 8 & Histidine & $21,105,114,224,323$ \\
\hline 9 & Glucine & $\begin{array}{l}33,101,104,106,131,160,225,279 \\
268,241,228,328,339\end{array}$ \\
\hline 10 & Glycine & $35,62,63,81,107,129,298,296$ \\
\hline 11 & Threonine & $36,85,172,264,270,280,325$ \\
\hline 12 & Isoleucine & $38,90,108,127,267,292,330$ \\
\hline 13 & Proline & $55,61,199,282,284,338$ \\
\hline 14 & Valine & $57,60,68,71,98,109,283$ \\
\hline 15 & Tyrosine & $59,79,95,165,240,125,278,291,329$ \\
\hline 16 & Glutamine & $73,77,203,285,288,327$ \\
\hline 17 & Trypsin & 294,302 \\
\hline 18 & Lysins & $80,82,97,100,130,227,340$ \\
\hline 19 & Methionine & 111,265 \\
\hline 20 & Phenylalanine & $169,200,301$ \\
\hline
\end{tabular}

Table 8: Active sites of the protein with PDB id 1IIH

\begin{tabular}{lll}
\hline S. No. & Amino acid & Active sites \\
\hline 1 & Cystine & $25,33,140$ \\
2 & Asparagine & $125,278,291,329$ \\
3 & Arginine & $57,60,68,71,98,109,283$ \\
4 & Alanine & $19,64,197,269$ \\
5 & Histidine & $21,105,114,224,323$ \\
6 & Glucine & $160,225,279,268,241,228,328,339$ \\
7 & Glycine & $35,62,63,81,107,129,298,296$ \\
8 & Threonine & $36,85,172,264,270,280,325$ \\
9 & Isoleucine & $33,101,104,106,131$ \\
10 & Proline & $33,81,27,267,292$ \\
11 & Valine & $57,60,68,71,98,109,283,240$ \\
12 & Tyrosine & $59,79,95,165$ \\
13 & Glutamine & $73,77,203,82,97,100,130,227$ \\
14 & Trypsin & $11,33,62$ \\
15 & Lysins & $80,285,288,32,73,40$ \\
\hline
\end{tabular}

Table 9: Binding of ligands with the pterine reductase

\begin{tabular}{llll}
\hline S. No. & Protein & Ligand & Binding enery \\
\hline 1 & Pterine reductase & Betulonic acid & $-7.698 \mathrm{kcal} / \mathrm{mol}$ \\
2 & Pterine reductase & Euglobal & $-8.24 \mathrm{kcal} / \mathrm{mol}$ \\
3 & Pterine reductase & Beta pinene & $-8.313 \mathrm{kcal} / \mathrm{mol}$ \\
4 & Pterine reductase & Alpha-pinene & $-10.18 \mathrm{kcal} / \mathrm{mol}$ \\
5 & Pterine reductase & P-Cymene & $-8.6045 \mathrm{kcal} / \mathrm{mol}$ \\
\hline
\end{tabular}

Table 10: Binding of ligands with adenosine monophosphate

\begin{tabular}{llll}
\hline S. No. & Protein & Ligand & Binding energy \\
\hline 1 & Adenosine monophosphate & Betulonic acid & $-9.544 \mathrm{kcal} / \mathrm{mol}$ \\
2 & Adenosine monophosphate & Euglobal & $-9.042 \mathrm{kcal} / \mathrm{mol}$ \\
3 & Adenosine monophosphate & Beta pinene & $-10.31 \mathrm{kcal} / \mathrm{mol}$ \\
4 & Adenosine monophosphate & Alpha pinene & $-8.844 \mathrm{kcal} / \mathrm{mol}$ \\
5 & Adenosine monophosphate & P-Cymene & $-8.386 \mathrm{kcal} / \mathrm{mol}$ \\
\hline
\end{tabular}

In Table 9, alpha-pinene has the minimum binding energy with pterine reductase.

In Table 10, beta-pinene has the minimum binding energy with adenosine monophosphate. 
Table 11: Binding of ligands with ornithine decarboxylase

\begin{tabular}{llll}
\hline S. No. & Protein & Ligand & Binding energy \\
\hline 1 & Ornithine decarboxylase & Betulonic acid & $-8.386 \mathrm{kcal} / \mathrm{mol}$ \\
2 & Ornithine decarboxylase & Euglobal & $-7.24 \mathrm{kcal} / \mathrm{mol}$ \\
3 & Ornithine decarboxylase & Beta-pinene & $-9.313 \mathrm{kcal} / \mathrm{mol}$ \\
4 & Ornithine decarboxylase & Alpha-pinene & $-10.18 \mathrm{kcal} / \mathrm{mol}$ \\
5 & Ornithine decarboxylase & P-Cymene & $-10.31 \mathrm{kcal} / \mathrm{mol}$ \\
\hline
\end{tabular}

Table 12: Binding of ligands with dihydrofolate reductase

\begin{tabular}{llll}
\hline S. No. & Protein & Ligand & Binding energy \\
\hline 1 & Dihydrofolate reductase & Betulonic acid & $-8.313 \mathrm{kcal} / \mathrm{mol}$ \\
2 & Dihydrofolate reductase & Euglobal & $-9.313 \mathrm{kcal} / \mathrm{mol}$ \\
3 & Dihydrofolate reductase & Beta-pinene & $-8.6045 \mathrm{kcal} / \mathrm{mol}$ \\
4 & Dihydrofolate reductase & Alpha-pinene & $-10.41 \mathrm{kcal} / \mathrm{mol}$ \\
5 & Dihydrofolate reductase & P-Cymene & $-10.15 \mathrm{kcal} / \mathrm{mol}$ \\
\hline
\end{tabular}

Table 13: Binding of ligands with dihydroorotate dehydrogenase

\begin{tabular}{llll}
\hline S. No. & Protein & Ligand & Binding energy \\
\hline 1 & $\begin{array}{l}\text { Dihydroorotate } \\
\text { dehydrogenase }\end{array}$ & Betulonic acid & $-8.14 \mathrm{kcal} / \mathrm{mol}$ \\
2 & $\begin{array}{l}\text { Dihydroorotate } \\
\text { dehydrogenase }\end{array}$ & Euglobal & $-10.24 \mathrm{kcal} / \mathrm{mol}$ \\
3 & $\begin{array}{l}\text { Dihydroorotate } \\
\text { dehydrogenase }\end{array}$ & Beta-pinene & $-9.16 \mathrm{kcal} / \mathrm{mol}$ \\
4 & $\begin{array}{l}\text { Dihydroorotate } \\
\text { dehydrogenase }\end{array}$ & Alpha-pinene & $-8.18 \mathrm{kcal} / \mathrm{mol}$ \\
5 & $\begin{array}{l}\text { Dihydroorotate } \\
\text { dehydrogenase }\end{array}$ & P-Cymene & $-9.28 \mathrm{kcal} / \mathrm{mol}$ \\
\hline
\end{tabular}

Table 14: Binding of ligands with TR

\begin{tabular}{llll}
\hline S. No. & Protein & Ligand & Binding energy \\
\hline 1 & TR & Betulonic acid & $-15.66 \mathrm{kcal} / \mathrm{mol}$ \\
2 & TR & Euglobal & $-9.24 \mathrm{kcal} / \mathrm{mol}$ \\
3 & TR & Beta-pinene & $-9.10 \mathrm{kcal} / \mathrm{mol}$ \\
4 & TR & Alpha-pinene & $-9.121 \mathrm{kcal} / \mathrm{mol}$ \\
5 & TR & P-Cymene & $-9.01 \mathrm{kcal} / \mathrm{mol}$ \\
\hline \multicolumn{2}{l}{ TR: Trypanothione reductase }
\end{tabular}

Table 15: Binding of ligands with HSP90

\begin{tabular}{llll}
\hline S. No. & Protein & Ligand & Binding energy \\
\hline 1 & HSP90 & Betulonic acid & $-6.325 \mathrm{kcal} / \mathrm{mol}$ \\
2 & HSP90 & Euglobal & $-6.589 \mathrm{kcal} / \mathrm{mol}$ \\
3 & HSP90 & Beta-pinene & $-7.546 \mathrm{kcal} / \mathrm{mol}$ \\
4 & HSP90 & Alpha-pinene & $-9.122 \mathrm{kcal} / \mathrm{mol}$ \\
5 & HSP90 & P-Cymene & $-8.045 \mathrm{kcal} / \mathrm{mol}$ \\
\hline
\end{tabular}

Table 16: Binding of ligands with adenosine kinase

\begin{tabular}{llll}
\hline S. No. & Protein & Ligand & Binding energy \\
\hline 1 & Adenosine kinase & Betulonic acid & $-7.66 \mathrm{kcal} / \mathrm{mol}$ \\
2 & Adenosine kinase & Euglobal & $-12.24 \mathrm{kcal} / \mathrm{mol}$ \\
3 & Adenosine kinase & Beta-pinene & $-10.313 \mathrm{kcal} / \mathrm{mol}$ \\
4 & Adenosine kinase & Alpha-pinene & $-10.3418 \mathrm{kcal} / \mathrm{mol}$ \\
5 & Adenosine kinase & P-Cymene & $-10.6045 \mathrm{kcal} / \mathrm{mol}$ \\
\hline
\end{tabular}

In Table 11, P-Cymene has the minimum binding energy with ornithine decarboxylase.

In Table 12, alpha-pinene has the minimum binding energy with dihydrofolate reductase.
Table 17: Binding of ligands with triosephosphate isomerase

\begin{tabular}{llll}
\hline S. No. & Protein & Ligand & Binding energy \\
\hline 1 & $\begin{array}{l}\text { Triosephosphate } \\
\text { isomerase }\end{array}$ & Betulonic acid & $-7.38 \mathrm{kcal} / \mathrm{mol}$ \\
2 & $\begin{array}{l}\text { Triosephosphate } \\
\text { isomerase }\end{array}$ & Euglobal & $-7.20 \mathrm{kcal} / \mathrm{mol}$ \\
3 & $\begin{array}{l}\text { Triosephosphate } \\
\text { isomerase }\end{array}$ & Beta pinene & $-9.114 \mathrm{kcal} / \mathrm{mol}$ \\
4 & $\begin{array}{l}\text { Triosephosphate } \\
\text { isomerase }\end{array}$ & Alpha pinene & $-9.364 \mathrm{kcal} / \mathrm{mol}$ \\
5 & $\begin{array}{l}\text { Triosephosphate } \\
\text { isomerase }\end{array}$ & P-Cymene & $-8.857 \mathrm{kcal} / \mathrm{mol}$ \\
& & & \\
\hline
\end{tabular}

Table 18: Binding of ligands with tyrosine kinase

\begin{tabular}{llll}
\hline S. No. & Protein & Ligand & Binding energy \\
\hline 1 & Tyrosine kinase & Betulonic acid & $-10.12 \mathrm{kcal} / \mathrm{mol}$ \\
2 & Tyrosine kinase & Euglobal & $-9.982 \mathrm{kcal} / \mathrm{mol}$ \\
3 & Tyrosine kinase & Beta pinene & $-9.642 \mathrm{kcal} / \mathrm{mol}$ \\
4 & Tyrosine kinase & Alpha pinene & $-10.3418 \mathrm{kcal} / \mathrm{mol}$ \\
5 & Tyrosine kinase & P-Cymene & $-9.954 \mathrm{Kcal} / \mathrm{mol}$ \\
\hline
\end{tabular}

In Table 13, Euglobal has the minimum binding energy with dihydrofolate reductase.

In Table 14, betulonic acid has the minimum binding energy with TR.

In Table 15, alpha-pinene has the minimum binding energy with HSP90.

In Table 16, P-Cymene has the minimum binding energy with adenosine kinase.

In Table 17, alpha-pinene has the minimum binding energy with triosephosphate isomerase.

In Table 18, betulonic acid has the minimum binding energy with tyrosine kinase.

Five compounds were selected from the extract of Eucalyptus tereticornis and subjected to interaction studies with the ten proteins associated with the sleeping sickness disease. The results of docking were compared to see the interaction, and the best binding energy is given in Table 19. Among 50 compounds, the best compound (shown in Table 19) was taken for further studies in QSAR.

In Table 19, betulonic acid has the minimum binding energy with TR (3QFX).

The docking scores were highest for betulonic acid with -15.66 $\mathrm{kcal} / \mathrm{mol}$ followed by euglobal with $-12.24 \mathrm{kcal} / \mathrm{mol}$, B-pinene with $-10.313 \mathrm{kcal} / \mathrm{mol}$, A-pinene with $-10.3418 \mathrm{kcal} / \mathrm{mol}$, and the least docking score for P-cymene with $-10.6045 \mathrm{kcal} / \mathrm{mol}$. Docking results showed that only betulonic acid and euglobal showed that hydrogen bond interaction was as b-pinene, a-pinene, and p-cymene yielded no hydrogen bond interactions. The best docking result was shown by betulonic acid with TR with a binding energy of $-15.66 \mathrm{kcal} / \mathrm{mol}$ with a hydrogen bond interaction of 2.9 angstroms, and this result was taken for further analysis in QSAR.

\section{DISCUSSION}

In this study, the molecular docking was applied to discover the binding [15] mechanism and to correlate its docking score with the activity of plant-derived compounds. The TR was subjected to molecular docking study with all the five E. tereticornis compounds that can act as antitrypanosomiasis drugs (either directly or indirectly). The studies by applying the docking technique yielded 
Table 19: Selected compounds with the least binding energy

\begin{tabular}{lllll}
\hline S. No & Protein & Ligand & Binding energy (kcal/mol) & No. of h-bond interactions (angstroms) \\
\hline 1 & Trypanothione reductase (3QFX) & Betulonic acid & -15.66 & $1(2.90000)$ \\
2 & Adenosine kinase (30TX) & Euglobal & -12.24 & $3(2.715618,2.947590$, and 2.454139) \\
3 & Adenosine kinase (30TX) & B-pinene & -10.31 & 0 \\
4 & Adenosine kinase (30TX) & A-pinene & -10.3418 & 0 \\
5 & Adenosine kinase (30TX) & P-cymene & -10.6045 & 0 \\
\hline
\end{tabular}

crucial information concerning the orientation of the inhibitors in the binding pocket of the target protein. Several potential inhibitors have been identified. The results of our present study suggested that it can be used for the design and development of novel compounds having better inhibitory activity against several types of trypanosomiasis. These potential drug candidates can be further be validated in wet lab studies for its proper function. In other words, the results of the present study can be concluded in the following points. Betulonic acid was better ligands of choice that inhibits TR antitrypanosomal protein than other ligands showing the best affinity to bind with the protein and showed outstanding score and energy when compared to all other compounds. By applying QSAR studies to the best-scored compounds, it also stands for both properties (drug likeness and orally bioavailability).

\section{CONCLUSION}

Human trypanosomiasis or sleeping sickness currently is a common disease among the rural regions though found rare in the city sides causing deaths in humans as well as livestock. Although continuing to decline in the city sides, yet incidence rates remain level in rural regions following an increase in India since 2007. Trends in human trypanosomiasis related death trends due to livestock and causative agents over the past several decades. In this field of structure-based drug designing, there is a growing interest in the human trypanosomiasis protein study for the screening of putative leaf compounds. This approach involves the structure-based study of trypanosoma proteins and the antitrypanosomal properties of the selected plant compounds based on the literature available. The active sites of the trypanosoma proteins were found out and the molecular docking of the plant compounds was performed. The five compounds were docked, from based on the binding energy and the number of hydrogen bonds. Among them betulonic acid, a compound in E. tereticornis is found to have the best binding affinity and strong hydrogen bond interaction with trypanosoma protein. Euglobal, B-pinene, A-pinene, and P-cymene also gave good scores.

The results of the compound extracted from E. tereticornis will become physiological relevant only when (i) the pure compounds of this plant are available in large quantities; (ii) the Eucalyptus is biochemically stabilized to avoid degradation and enhance absorption in the gastrointestinal tract; and (iii) special delivery methods for this drug to reach the areas of treatment. In this work, the efficacy of E. tereticornis to act against trypanosomal protein was initiated and thus further research in this process would help us to take full advantage of the remedial effects of the compounds extracted from this plant. Solving these issues in the future would help the in vitro and in vivo studies to enhance the possibility of using Eucalyptus in clinical practice. The below mentioned wet-lab studies were possible that can be carried out in future can be listed as below: (i) The synergistic effect of TR can be tested with other compounds; (ii) to test how far these are useful in combinatory chemotherapies; (iii) its role in targeting multiple arms of the immune system machinery; (iv) identification and effect of structurally modified E. tereticornis compounds as trypanosomal inhibitors; and (v) real-life challenges and possibility in bringing up these inhibitors as orally available drugs or even as energy drinks.

\section{AUTHORS' CONTRIBUTIONS}

Aarthi Rashmi B guided the research. Vasanth Nirmal Bosco supervised the research. Priyanka K interpreted the results. Harishchander A prepared the manuscript with a highlight on critical points.

\section{CONFLICTS OF INTEREST}

The authors declare that they have no conflicts of interest.

\section{REFERENCES}

1. Barrett MP, Boykin DW, Brun R, Tidwell RR. Human African trypanosomiasis: Pharmacological re-engagement with a neglected disease. Br J Pharmacol 2017;152:1155-71.

2. Dawson A, Gibellini F, Sienkiewicz N, Tulloch LB, Fyfe PK. Structure and reactivity of Trypanosoma brucei pteridine reductase: Inhibition by the archetypal antifolate methotrexate. Mol Microbol 2013;61:1457-68.

3. Gamarro F, Yu PL, Zhao J, Edman U, Greene PJ. Trypansoma brucei dihydrofolate reductase-thymidylate synthase: Gene isolation and expression and characterization of the enzyme. Mol Biochem Parasitol 2017;72:11-22.

4. Krieger S, Schwarz W, Ariyanayagam MR, Fairlamb AH, Krauth-Siegel RL. Trypanosomes lacking trypanothione reductase are avirulent and show increased sensitivity to oxidativex stress. Mol Microbiol 2018;35:542-52.

5. Mackey ZB, O'Brien TC, Greenbaum DC, Blank RB, McKerrow JH. A cathepsin B-like protease is required for host protein degradation in Trypanosoma brucei. J Biol Chem 2014;279:48426-33.

6. Pallavi R, Roy N, Nageshan RK, Talukdar P, Pavithra SR. Heat shock protein 90 as a drug target against protozoan infections. Biochemical and evaluation of its inhibitor as a candidate drug. J Biol Chem 2012;285:37964-75.

7. Lepesheva GI, Park HW, Hargrove TY, Vanhollebeke B, Wawrzak Z. Crystal structures of Trypanosoma brucei sterol 14 $\alpha$-demethylase and implications for selective treatment of human infections. J Biol Chem 2010;285:1773-80

8. Parkin DW. Purine-specific nucleoside N-ribohydrolase from Trypanosoma brucei. J Biol Chem 2013;271:21713-9.

9. Helfert S, Estévez AM, Bakker B, Michels P, Clayton C. Roles of triosephosphate isomerase and aerobic metabolism in Trypanosoma brucei. Biochem J 2011;357:117-25.

10. Bosch J, Robien MA, Mehlin C, Boni E, Riechers A. Using fragment cocktail crystallography to assist inhibitor design of Trypanosoma brucei nucleoside 2-deoxyribosyltransferase. J Med Chem 2012;49:5939-46.

11. Shaw MP, Bond CS, Roper JR, Gourley DG, Ferguson MA. Highresolution crystal structure of Trypanosoma brucei UDP-galactose 4'-epimerase: A potential target for structure-based development of novel trypanocides. Mol Biochem Parasitol 2013;126:173-80.

12. Harishchander A, Anand DA. Computational approach for identifying therapeutic micro RNAs. Int J Pharm Pharm Sci 2014;6:638-40.

13. Zumaana R, Saranya S, Rama V. Computational docking and in silico analysis of potential efflux pump inhibitor punigratane. Int J Pharm Pharm Sci 2014;10:27-34.

14. Anand DA, Harishchander A, Jason UB. An integrated network analysis of psoriasis: A novel approach to disease pathology. Asian J Pharm Clin Res 2015;8:176-8.

15. Anandaram H, Anand DA. Binding site analysis of micrornas target interaction from genome wide association studies. Asian J Pharm Clin Res 2014;7:121-2. 